\title{
Homilía
}

\section{"En pie de testimonio"}

\author{
P. Rodolfo Cardenal \\ en la eucaristía del XVI Aniversario de Monseñor Romero
}

Este aniversario que celebramos de Monseñor Romero está marcado por dos novedades en relación a los aniversarios anteriores.

La primera novedad consiste en que una parte importante del pueblo salvadoreño, quizás impaciente por la lentitud de la burocracia eclesiástica, pide a gritos la canonización de Monseñor Romero. Es un fenómeno nuevo haber gritado — todas las veces que hubo oportunidad para ello- que queremos que Monseñor Romero sea reconocido oficialmente por la Iglesia universal como un santo.

El mensaje ha llegado. Según algunos informes de prensa internacional, hasta en la. misma sala de audiencias del Papa en Roma se escuchado el mismo grito. En efecto, poco después de la visita de Juan Pablo II a El Salvador allí también hubo gritos pidiendo la canonización de Monseñor Romero. De modo que Juan Pablo II ya lo repite con bastante frecuencia. Muchos quieren que Monseñor Romero sea canonizado y El Salvador es el lugar donde piden a gritos su canonización.

Pero sabemos también que no todos quieren la canonización de Monseñor Romero. Sabemos perféctamente bien que Monseñor Romero estuvo ausente en el templete, donde Juan Pablo II presidió la eucaristía en el país. Estuvo ausente en la homilía e incluso hubo intentos para que el Papa no visitara la catedral. Pero por esas cosas que tiene la historia, el Vaticano decidió que el Papa visitaría la catedral de San Salvador y no el estadio que le estaban proponiendo y el pueblo reunido en la plaza Cívica pidió a gritos la canonización. Este grito popular ha quedado ya como una huella imborrable en la Iglesia salvadoreña. 
Y esto, ¿por qué sucede? Porque Monseñor Romero es sumamente importante para El Salvador y no solamente para la Iglesia. Monseñor Romero es probablemente el salvadoreño más importante de toda la historia del país y lo es de una manera muy especial: Monseñor Romero da identidad. Ser salvadoreño o salvadoreña es ser del país de donde es Monseñor Romero. Ser salvadoreño es de alguna manera estar identificado con Monseñor Romero. Ser salvadoreño es admirar a Monseñor Romero. En ese sentido Monseñor Romero da identidad, identidad de pueblo, identidad de país, identidad de nación. Generó identidad durante su vida y la sigue generando hasta el día de hoy, a pesar de su muerte.

Es interesante observar que en este aniversario se nota más animación en las en las comunidades, en las parroquias y en las calles de San Salvador. Se constata un deseo profundo por celebrar a Monseñor Romero con eucaristías, actos culturales e incluso con manifestaciones. Se nota el deseo por proclamar la identidad que su persona y su obra han generado en El Salvador y fuera de él. Y junto a la identidad, Monseñor Romero es muy importante porque da esperanza, como lo acabamos de escuchar hoy en sus propias palabras: la esperanza del reino de Dios y de que haya justicia. Seguimos esperando que el proyecto de país se aproxime cada vez más al reino de Dios. Esta esperanza sigue siendo muy importante porque es obvio que cada vez es más grande la diferencia entre El Salvador de hoy y el reino de Dios. En lugar de aproximarnos a él, nos alejamos cada vez más. Las cúpulas eclesiástica y estatal se habrán aproximado como nunca antes, pero el país en cuanto tal se aleja cada día más del reino de Dios.

Monseñor Romero da esperanza, sigue siendo esperanza, sigue siendo aquel obispo que, abandonando su timidez y sus miedos, cuando vio el sufrimiento de aquel pueblo, se lanzó a hablar por ese pueblo, dándole voz. Pidió y clamó justicia. Y también por esa razón es el salvadoreño más universal. El 24 de marzo se recuerda a Monseñor Romero no sólo aquí, sino prácticamente en todo el mundo. Se le recuerda como un gran salvadoreño, pero sobre todo como el salvadoreño que luchó por la justicia, que dio su vida por su pueblo. Se le recuerda como la gran esperanza de lo que significa ser cristiano, ser sacerdote y ser obispo.

En este sentido, Monseñor Romero no es propiedad exclusiva de la Iglesia ni de los procesos eclesiásticos de canonización. Estos son importantes e, indudablemente, se debe seguir adelante con los procedimientos establecidos por el derecho canónico. Pero hay que entender también que Monseñor Romero es más grande que la Iglesia institucional, que un proceso eclesiástico de canonización. Monseñor 


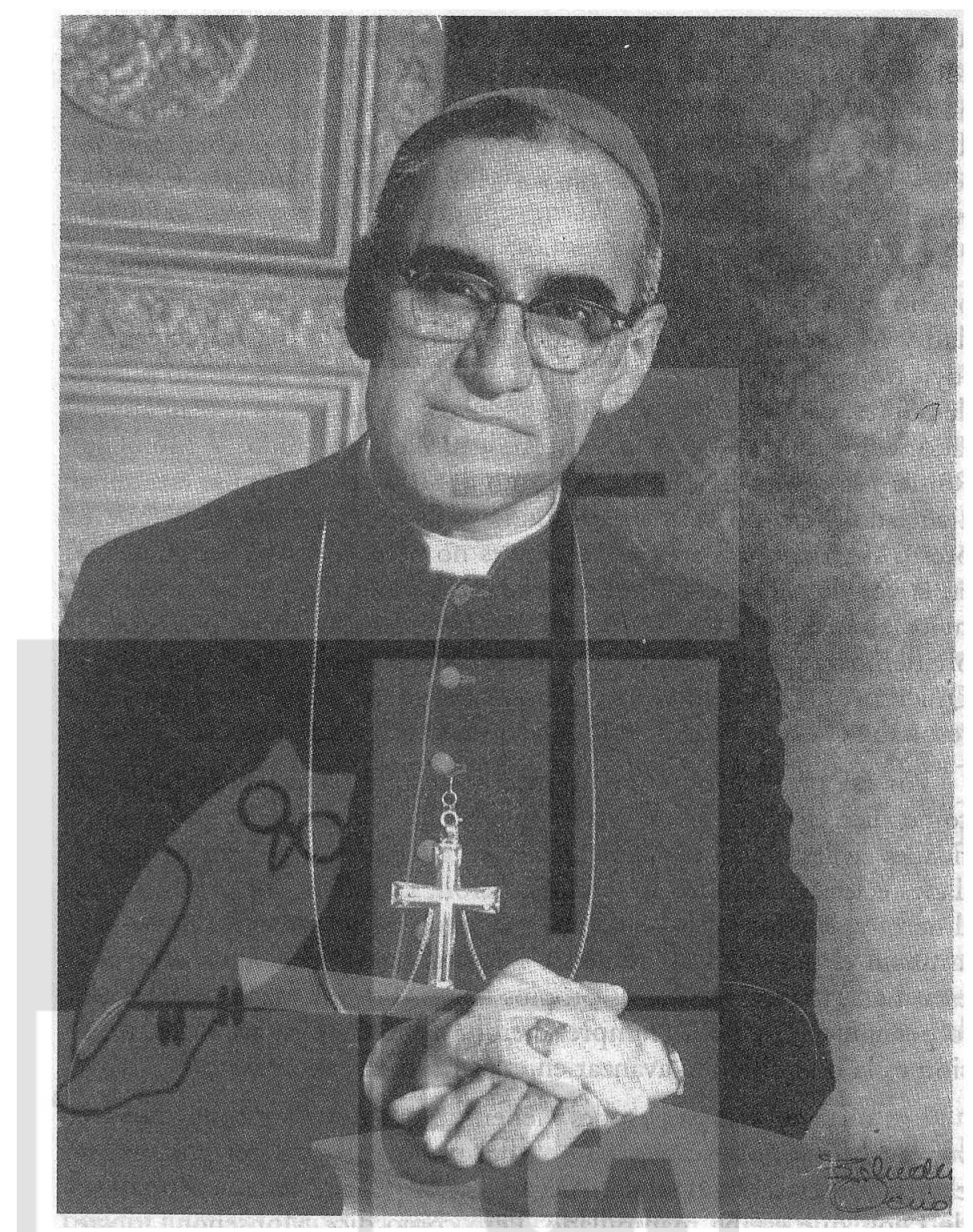

Romero está más allá del control de los eclesiásticos. Romero vive en su pueblo y en la comunidad internacional. Vive generando esperanza y es bueno que así sea, que se proyecte más allá de la Iglesia.

En segundo lugar, la otra novedad que encontramos en este aniversario es un intento bastante claro por silenciar lo más característico de Monseñor Romero. Existe una tendencia que se esfuerza por presentar a Monseñor Romero como el hombre bueno, el hombre de Dios, el hombre piadoso, el hombre de oración. Todo ello es cierto. Monseñor Romero fue un hombre bueno, piadoso y de oración. Fue 
un hombre de Dios. Quienes lo conocieron lo saben y quienes no lo conocieron lo pueden constatar en su diario. No solamente era un hombre bueno y un hombre de Dios, sino que era un hombre de una devoción profunda. Poseía la devoción tan propia del pueblo salvadoreño. Pero eso no es lo que hizo a Monseñor Romero grande y universal.

En El Salvador, a Dios gracias, hay muchos hombres y mujeres buenos, devotos y piadosos. Hombres y mujeres de Dios todavía quedan y Monseñor Romero fue uno de ellos. Pero lo más característico suyo fue que entendió a la Iglesia como pueblo de Dios, como pueblo de pobres, como pueblo de madres sin hijos, porque se los habían arrebatado, como pueblo de víctimas, como pueblo crucificado. Y Monseñor Romero se compadeció del sufrimiento de su pueblo y se puso a caminar a su lado. Pero no solamente caminó al lado del pueblo, sino que le prestó su voz, porque en ese entonces no había voz para ese pueblo. Y en la voz de Monseñor Romero resonó el clamor del pueblo y por eso su palabra queda. Eso es lo que quieren silenciar ahora para que lo olvidemos: que lo grande de Monseñor Romero fue su profecía. Quieren que olvidemos su palabra, que no era suya, porque en ella resonaba el clamor del pueblo salvadoreño exigiendo justicia.

Por esa razón Monseñor Romero se enfrentó a las autoridades, tal como dice el evangelio de Mateo que hemos leído. Se enfrentó a autoridades civiles, militares y lamentablemente también se enfrentó a autoridades eclesiásticas, que no lo entendieron. Denunció los proyectos del dinero y la violencia - la idolatría decía Monseñor Romero-, y anunció el proyecto del reino de Dios tal como lo hemos escuchado esta mañana otra vez de sus propios labios. Por esa razón lo atacaron, lo persiguieron y no lo comprendieron. En definitiva, esa incomprensión es la que dificulta avanzar en el proceso de canonización.

Los obstáculos más grandes vienen de quienes no reconocen en la voz de Monseñor Romero la voz del profeta, la voz del pueblo que clama. Ahí está la dificultad. Alegan que es política, que no es palabra de Dios, que estaba manipulado. Pero como dice Monseñor Urioste, si de alguien se dejó manipular Monseñor Romero fue de Dios y solamente de Dios. Por lo tanto, pídanle cuentas a Dios y no a Monseñor Romero. El que tiene que responder de los actos proféticos de Monseñor Romero es Dios mismo. Monseñor Romero se puso en las manos de Dios y se dejó llevar por él a donde él no quería y a donde él probablemente nunca en su vida pensó que podría llevarlo Dios.

Pero se dejó llevar. Fue el profeta de Dios, enviado en uno de los momentos más críticos del pueblo salvadoreño. Por esa razón, en Monseñor Romero se cumple el evangelio de hoy. El evangelio que hemos leído 
está dentro del discurso de la misión. Cuando Jesús envía a sus discípulos, los manda a anunciar el evangelio. La misión de Jesús tiene bastante aceptación, pero al final, Jesús advierte a sus discípulos: los mando como ovejas entre lobos, ustedes van porque yo los envío. No es voluntad del enviado. El discípulo es un mandado como se dice en buen salvadoreño. Monseñor Romero fue enviado. Es claro que él no lo quería, él no lo pidió, nunca lo soñó, pero fue mandado entre los lobos para anunciar el reino de Dios y denunciar las idolatrías del dinero y la violencia.

En la obra teatral "El martirio del pastor", que la compañía de teatro universitario de la UCA está presentando en estos días, se muestra con claridad por qué viene la persecución, la difamación, el insulto y la comparecencia ante los tribunales. Monseñor Romero estuvo a punto de ser llevado a un tribunal por denunciar que los jueces eran venales. No lo pudieron coger en falta y los hechos han demostrado que estaba en lo correcto. Los jueces eran venales y siguen siendo venales. Los medios de comunicación social también enjuiciaron a Monseñor Romero. Los mismos medios que en la actualidad se precian mucho de la libertad de expresión lo acusaron, lo insultaron, lo difamaron y tergiversaron sus palabras. Es interesante volver sobre algunos de los periódicos de ese entonces para constatar la miseria humana que se echó sobre Monsenor Romero. Los grandes medios de comunicación que en la actualidad se enorgullecen de su trayectoria de lucha en favor de la libertad no han reconocido sus errores ni mucho menos han pedido perdón.

También Monseñor Romero fue llevado a los tribunales eclesiásticos. Primero le mandaron avisos y después llegaron los visitadores eclesiásticos. Finalmente, le cerraron las puertas en Roma. En su diario se relata con bastante detalle cómo le impidieron el acceso al Papa.

Pero como dice el evangelio de hoy, todo esto sucede para dar testimonio de Jesús, para dar testimonio de la verdad. Cuando el discípulo es llevado a los tribunales, cuando es acusado y debe responder ante sus jueces, el que habla es el Espíritu de Jesús. Monseñor Romero fue enviado al pueblo salvadoreño y por su boca habló el Espíritu Santo. El le inspiró lo que tenía que decir. No se preocupen, dice el evangelio, él hablará por ustedes. No obstante haber transcurrido dieciséis años desde su asesinato, Monseñor Romero sigue hablando hoy a muchos.

El profeta que se enfrentá a esta adversidad y persecución, sufre un gran desgarramiento. Es separado de amigos, familiares y conocidos. Ese desgarramiento también lo vivió Monseñor Romero. El padre acusará a los hijos, los hermanos se pondrán contra los hermanos, 
dice el evangelio. Los amigos que rodearon a Monseñor Romero cuando llegó a San Salvador lo abandonaron. Los obispos de entonces también estuvieron en contra suya, tal como se puede constatar en las actas de la conferencia episcopal y en su propio diario. Lo acusaron dura e injustamente. Le dieron la espalda. Sólo Monseñor Rivera lo defendió y levantó su voz junto con la suya. Monseñor Romero sufrió abandonos y soledades, traiciones y dudas sobre si estaba haciendo la voluntad de Dios. Cuando el discípulo llega a estas alturas de la misión sólo le quedan Dios y el pueblo, la fidelidad a Dios y al pueblo al que ha sido enviado como profeta y pastor.

Por esa razón estamos hoy aquí. Como dice dom Pedro Casaldáliga en su bellísima oración poesía dedicada a San Romero de América, "estamos en pie de testimonio" porque es 24 de marzo, porque es Romero, porque es San Romero de América. Pero debemos estar en pie de testimonio porque sigue habiendo pobreza, porque se sigue persiguiendo a los pobres con la ley, porque no se hace justicia, porque hay tanto desengaño histórico.

Con mucha propiedad el afiche conmemorativo del Centro Monseñor Romero de la UCA nos recuerda una frase suya que tiene una gran actualidad: "Los pobres son los que dicen qué es el mundo y cuál es el servicio que la Iglesia debe prestar al mundo". ¿Quieren saber cómo está el mundo? Miren a los pobres. Los pobres nos dicen cómo está el mundo. No lo dicen los políticos, no lo dicen los medios de comunicación, no lo dicen los analistas. Hay que mirar a los pobres para saber cómo está esta sociedad y también para saber lo que debemos hacer como cristianos y seguidores de Jesús. En este sentido podemos preguntarnos quién hablará hoy, a quién enviará el Señor, quién prestará su voz, quién asumirá la causa de los pobres, quién hará suya su defensa. Monseñor Romero sabía que él tenía un don y una misión, pero decía: todos debemos ser los micrófonos de Dios, todos debemos hablar, todos debemos decir nuestra palabra.

Desde el lado civil hoy también nos dicen "que hable la sociedad, que los civiles expresen sus necesidades, que las organizaciones no gubernamentales vigilen, que la sociedad opine. Desde el punto de vista cristiano, todos debemos decir nuestra palabra, todos debemos estar en pie de testimonio, testimonio de lo que está pasando en el país, de lo está pasando a los pobres. En pie de testimonio de nuestra fe y de nuestra esperanza.

Ya no está Monseñor Romero físicamente con nosotros, pero está su ejemplo. Su palabra queda y ojalá que nuestra palabra quede también, la de todos. Ojalá que nosotros también oigamos ese clamor del pueblo, ese clamor de Dios que también se pregunta: ‘a quién enviaré? ¿Quién asumirá la causa de los pobres? 
Que esta conmemoración del asesinato-martirio de Monseñor Romero nos ayude a todos a ponernos en pie de testimonio. Quizás ahora hay que dar una batalla más difícil que durante la época de la guerra. Quizás ahora sea más duro, más desconcertante y más cuesta arriba. Pero ahí está Monseñor Romero que nos ofrece su fuerza para seguir dando testimonio y no doblegarnos, para no dejarnos engañar, para seguir hablando.

Que el Señor, pues, nos ayude, que él nos dé su fuerza para que oigamos ese clamor y nosotros sigamos también pronunciando esa palabra de salvación. Así sea.

San Salvador, 24 de marzo de 1996. 